BOLETIM DE PESQUISA NELIC: Edição Especial $V^{\circ} 3$ - Dossiê Murilo Mendes / Ana Cristina Cesar

APRESENTAÇÃO 
A edição especial do Boletim de Pesquisa do Núcleo de Estudos literários e Culturais - NELIC - é duas homenagens a duas obras poéticas: a de Murilo Mendes e a de Ana Cristina Cesar.

A de Murilo Mendes é o resultado da homenagem que o grupo de pesquisadores da poesia moderna brasileira do NELIC dedicou à obra de Murilo Mendes. O dia 8 de março de 2010 foi a data escolhida para culminar o processo que começou em abril de 2009. Durante os encontros que ocorreram ao longo de um ano, lemos toda a obra do poeta Murilo Mendes. Foram lidos os poemas dos livros de poesia e os da prosa poética, a crítica acadêmica dessa obra também foi contemplada nas discussões que fomentamos. Depois de meses de elaboração das leituras dos participantes dos seminários, decidiu-se pela apresentação à comunidade acadêmica da Universidade Federal de Santa Catarina dos textos que resultaram desse estudo como uma forma também de homenagear essa que é uma das mais fecundas experiências poéticas da modernidade brasileira. Dessa homenagem participaram os líderes do Grupo de pesquisadores reunidos no NELIC, os professores Maria Lúcia de Barros Camargo, com uma conferência de abertura sobre a obra de Murilo Mendes, e Raúl Antelo, com a conferência de 
encerramento da homenagem, "Murilo, ele saberia quem é Murilo Mendes?". Participaram dos encontros os mestrandos, Evandro de Sousa, com o texto “'A inteligência': Fantasma (d)e fantasia em Murilo Mendes", Renata Gomes, "Murilo Mendes e Elizabeth Bishop: poesia abstrata em Ouro Preto", Diego Cervelin, com o texto "Fragmentos de tempo - ecos imemoriais", e Luciana Tiscoski, autora do texto "Ascese e Imagem Poética no encontro entre Jorge de Lima e Murilo Mendes" , e o doutorando George França, autor do texto "A harpa, o quadro e a sereia: Murilo Mendes, Vieira da Silva e Arpad Szenes". Na qualidade de editora do Boletim de Pesquisa do NELIC organizei e tenho a honra de apresentar ao público leitor esta edição especial fruto do trabalho dos Seminários de Poesia de nosso núcleo de pesquisa com os textos produzidos a partir da leitura da obra de Murilo Mendes.

Nesta edição publicamos também uma homenagem à poesia de Ana Cristina Cesar. Os textos apresentados são resultado do curso que a professora Maria Lucia de Barros Camargo e o professor Manuel Ricardo de Lima ofereceram no programa de Pós-Graduação em Literatura da UFSC, em 2009. Aqui publicamos os textos de Renata Gonçalves Gomes, "Olhos pardos e Olhos Vermelhos: Ana C. \& Chacal", de Davi Pessoa
Boletim de Pesquisa NELIC - Edição Especial V. 32010.1

Carneiro Barbosa, "A pertinência das aspas: a leitura em Ana Cristina Cesar", de Luiza Possebon Ribas, "Ana C. e Caio F.: encontros de corpos e das escrituras", de Fernando Floriani Petry, "Ana Cristina Cesar e Manuel de Barros - Confluências possíveis", de Camila Morgana Lourenço, "Ana Cristina Cesar e Caio Fernando de Abreu: literaturas entre amigos", de Ana Carolina Cernicchiaro, "O outro de Ana Cristina Cesar: WW ou um outro qualquer", de Cristiane Roveda Gonçalves, "Quem tem medo de Ana Cristina Cesar", de Laíse Ribas Bastos, "Entre Ana Cristina Cesar, o nome e o texto".

\section{Susana Scramim}

Editora Científica do Boletim de Pesquisas do NELIC 